\title{
Relationship between natriuretic peptides and echocardiography parameters in patients with poorly regulated type 2 diabetes
}

\author{
This article was published in the following Dove Press journal: \\ Vascular Health and Risk Management \\ 14 April 2010 \\ Number of times this article has been viewed
}

\author{
Magnus Dencker' \\ Martin Stagmo ${ }^{2}$ \\ Mozhgan Dorkhan ${ }^{3}$ \\ 'Unit of Clinical Physiology and \\ Nuclear Medicine, Department \\ of Clinical Sciences, ${ }^{2}$ Division of \\ Cardiology, ${ }^{3}$ Division of Diabetes \\ and Endocrinology, Malmö University \\ Hospital, Malmö, Sweden
}

\begin{abstract}
This study evaluated the relationship between natriuretic peptide levels and a wide range of echocardiography parameters in a population of thirty-three patients with poorly regulated type 2 diabetes, and no known heart failure. Natriuretic peptides brain natriuretic peptide (BNP) and N-terminal prohormone BNP (NT-proBNP) were measured. Transthoracic echocardiography was performed and cardiac volumes and ejection fraction were measured. Doppler and tissue Doppler were measured and diastolic function was stratified according to recent guidelines. Very few echocardiography parameters were correlated with BNP or NT-proBNP levels. However, left atrial end-systolic volume indexed for body surface area was correlated with natural logarithm $(\ln )$ BNP and $\ln$ NT-proBNP $(r=0.62$ and $r=0.60$; $P<0.05)$. There were significant differences in $\ln$ BNP and ln NT-proBNP levels between those with normal and those with abnormal diastolic function (1.4 vs $3.1 ; P<0.001$ and 3.4 vs 5.8; $P<0.001)$. This study showed that very few echocardiography parameters were correlated with BNP or NT-proBNP levels in patients with poorly regulated type 2 diabetes, which in part contradicts previous studies in other diabetic populations. The exception was left atrial end-systolic volume that showed a moderate correlation with BNP or NT-proBNP levels. There were significant differences in BNP and NT-proBNP levels between the group with normal left ventricular diastolic function and the group with abnormal diastolic function.
\end{abstract}

Keywords: type 2 diabetes, natriuretic peptides, echocardiography

\section{Introduction}

Patients with type 2 diabetes (T2D) have an enhanced risk of contracting cardiovascular diseases. ${ }^{1-3}$ Much of the cardiovascular morbidity and mortality is driven by congestive heart failure (CHF). It is important, therefore, to identify early those who have subclinical heart dysfunction. Biomarkers such as brain natriuretic peptide (BNP) and N-terminal prohormone BNP (NT-proBNP) have been suggested as a screening tool in a variety of cardiac conditions. ${ }^{4-8}$

Patients with poorly regulated T2D are of special interest as they are candidates for add-on therapy with either insulin and/or thiazolidinediones, ${ }^{9}$ which may cause fluid retention, weight gain, and in a few cases, CHF. ${ }^{10}$ Moreover, previous studies examining the relationship between BNP and NT-proBNP versus echocardiography in diabetic patients have given diverging findings. ${ }^{11-14}$ This could, in part, be due to different diabetic populations and diverging echocardiography protocols.

There are no studies, to our knowledge, that have investigated the correlation between natriuretic peptide levels and the wide range of prognostic echocardiography parameters in a population of patients with poorly regulated T2D and no known
Correspondence: Magnus Dencker Department of Clinical Sciences Unit of Clinical Physiology and Nuclear Medicine Malmö University Hospital MAS 20502 Malmö, Sweden

Tel +46403 3873I

Fax +4640338768

Email magnus.dencker@skane.se 
congestive heart disease. The present study thus evaluated the relationships between natriuretic peptides and a variety of echocardiography parameters in such a population.

\section{Material and methods Patients}

Thirty-three consecutive patients with T2D and inadequate glycemic control, without known heart failure, were included in the study. Inadequate glycemic control was defined as treatment with metformin and sulfonylurea/meglitinide in doses $>50 \%$ of maximum recommended doses and hemoglobin $\mathrm{A}_{1 \mathrm{c}}\left(\mathrm{HbA}_{1 \mathrm{c}}\right)>6.2 \%$ measured with Mono-S method (= 7\% National Glycohemoglobin Standardization Program, NGSP). Height and body mass were measured, and body mass index (BMI) was calculated. Body surface area (BSA) was calculated as (height in $\mathrm{cm}$ ) $0.725 \times$ (body mass in $\mathrm{kg}$ ) $0.425 \times 0.00718 .{ }^{15}$ Blood samples for the measurement of BNP and NT-proBNP were collected after at least 10 minutes rest in the supine position. All blood samples were drawn after an overnight fast. Estimated glomerular filtration rate (eGFR) was calculated according to the Cockroft-Gaults formula. Blood pressure was measured in the right arm after 5 minutes rest in the supine position. Exclusion criteria were clinical signs of heart failure according to New York Heart Association (NYHA) or the presence of a heart murmur on auscultation. Echocardiography exclusion criteria were an inappropriate acoustic window or nonsinus rhythm. In the study population, three patients have had previous myocardial infarct and one patient had undergone a prior coronary artery bypass graft (CABG). Written informed consent was obtained from all participating patients. The institutional ethics committee of the Lund University, Sweden, approved the study.

\section{Echocardiography}

Transthoracic echocardiography examinations were performed with Sonos 5500 (Philips, Andover, MA, USA). A single observer blinded to all clinical data performed all echocardiography measurements, which were performed twice. The mean value was used in all analysis. From two dimensional (2-D) echocardiography, left ventricular end-diastolic diameter (LVDD), posterior wall thickness (POST) and interventricularseptum thickness (IVS) were measured and left ventricular mass (LVM) was calculated from the formula $\mathrm{LVM}=0.8 \times 1.04 \times(\mathrm{LVDD}$ + IVS + POST $)^{3}-$ LVDD $^{3}+0.6 .{ }^{16}$ Left ventricular enddiastolic volume (LVDV), left ventricular end-systolic volume (LVSV) and left atrial end-systolic volume (LAV) were quantified by biplane method of discs. All volume measurements, LVM, POST and IVS were indexed for BSA (LVDVI, LVSVI, LAVI, LVMI, POSTI, IVSI). Ejection fraction (EF) was quantified by biplane method of discs. ${ }^{16}$

Pulsed Doppler parameters were measured from the apical four chamber view at the tip of the mitral leaflets and peak of early diastolic (E) and late diastolic (A) mitral flow velocities. E/A ratio, and deceleration time (DT) of E-wave were measured. Pulmonary veins were viewed from the apical four chamber view and the pulmonary vein peak velocities during systole (S) and diastole (D) were measured with pulsed Doppler. S/D ratio was calculated.

Pulsed tissue Doppler imaging (TDI) of the medial and lateral mitral annulus was obtained from the apical four chamber view. Peak systolic (Sm), early (Em) and late (Am) mitral annular diastolic velocities were measured both at the septal and lateral annulus. The ratios for Em/Am and E/Em were calculated, with Em averaged from septal and lateral wall. TDI of the free right ventricular wall was obtained in the tricuspid annulus and Sm, Em, and Am were measured.

The subject's left ventricular diastolic function was classified according to recent guidelines and graded from 1 to 4 , with grade 1 representing normal and grade 2-4 representing escalating degrees of abnormal diastolic function. ${ }^{17}$ We based our grading of diastolic function on the following variables: Em, LAVI, E/A, and DT. ${ }^{17}$

The subject's left ventricular filling pressure was estimated according to recent guidelines and classified as normal or elevated. ${ }^{17} \mathrm{We}$ based our estimation of filling pressure on E/Em and LAVI. ${ }^{17}$

\section{Assays}

BNP was measured with an immunoassay system from Beckman (Biosite, CA, USA) with a coefficient of variance (CV) of 3.5\% and NT-proBNP using an immunometric method (Hitachi Modular-E; Roche, Mannheim, Germany) with a $\mathrm{CV}$ of $4.4 \%$.

\section{Statistical methods}

Data are presented as means \pm SD. Statistical analyses were carried out using Statistica 7.1 (StatSoft Inc, Tulsa, OK, USA). Skewed values were normalized by $\ln$, values without logarithmic transformation are also presented for the sake of simplicity. Univariate relationships between $\ln$ BNP or ln NT-proBNP and various variables were assessed with Pearson correlation analysis, with adjustment made for sex. Stepwise multiple forward regression analyses, with intercept, were used to evaluate the independency in the relationship between 
BNP or NT-proBNP versus LAVI. In these models, BNP or NT-proBNP were dependent variables and LAVI, age, body mass, and sex were introduced into the model as independent variables. Receiver-operator characteristic analysis was not performed due to the limited number of subjects. Student's $t$-test between means was used to analyse group differences. Statistical significance was set at a level of $P<0.05$.

\section{Results}

All subjects had acceptable measurements and an EF $>50 \%$. No patient had significant valve disease. Table 1 displays descriptive statistics of the study population. BNP and NT-proBNP showed very little correlation with the various echocardiography parameters. Table 2 displays Pearson correlation coefficients between ln BNP and ln NT-proBNP versus the echocardiography parameters. The salient exception was LAVI, which showed a moderate relationship with both BNP and NT-proBNP levels. Multiple regression analyses indicated that LAVI alone explained $35 \%$ of the variance in BNP concentrations $\left(r^{2}=0.35\right)$, whereas the other variables that entered the model added nothing significant. A similar result was found for NT-proBNP concentrations $\left(\mathrm{r}^{2}=0.33\right)$, where LAVI alone explained $33 \%$ of the variance with the other variables adding nothing significant. Figures 1 and 2 display the unadjusted relationship between LAVI versus ln BNP and ln NT-proBNP.

A total of 29 subjects had grade 1 diastolic function (normal), two had grade 2, and two had grade 3 . The individuals who had grade 2 and 3 were pooled together as abnormal in further analyses. There were significant differences between these groups, despite the modest sample size. Ln BNP and ln NT-proBNP levels for those with normal and for those with abnormal diastolic function were $1.4 \mathrm{vs} 3.1$ $(P<0.001)$ and 3.4 vs $5.8(P<0.001)$, respectively. Table 3 is a summary of anthropometric, laboratory, and selected echocardiography characteristics for those with normal versus those with abnormal diastolic function. Figures 3 and 4 displays the $\ln \mathrm{BNP}$ and $\ln$ NT-proBNP values according to diastolic function.

A total of 25 subjects had normal filling pressure, as estimated by echocardiography, and eight subjects had indications of elevated filling pressure. There were no significant differences between those with normal compared to those with elevated filling pressure; $\ln$ BNP 1.5 vs 1.9 and in NT-proBNP 3.5 vs $4.0, P>0.20$ for both. Table 4 is a summary of anthropometric, laboratory, and selected echocardiography characteristics for those with normal versus those with elevated filling pressure.
Table I Subjects' anthropometric, echocardiography and laboratory characteristics. Values are mean \pm SD

\begin{tabular}{|c|c|}
\hline Men/women & $23 / 10$ \\
\hline Age (yrs) & $61.4 \pm 7.4$ \\
\hline Height (cm) & $170.9 \pm 9.0$ \\
\hline Body mass (kg) & $90.4 \pm 16.5$ \\
\hline BMI $\left(\mathrm{kg} / \mathrm{m}^{2}\right)$ & $31.0 \pm 5.6$ \\
\hline BSA $\left(m^{2}\right)$ & $2.0 \pm 0.2$ \\
\hline Diabetes duration (years) & $9.8 \pm 6.2$ \\
\hline $\mathrm{HbA}_{\mathrm{Ic}}(\%)$ & $8.2 \pm 1.4$ \\
\hline Systolic blood pressure $(\mathrm{mm} \mathrm{Hg})$ & $144 \pm 17$ \\
\hline Diastolic blood pressure $(\mathrm{mm} \mathrm{Hg})$ & $83 \pm 8$ \\
\hline $\mathrm{BNP}(\mathrm{pmol} / \mathrm{l})$ & $7.8 \pm 9.3$ \\
\hline eGFR (ml/min) & $117 \pm 39$ \\
\hline NT-proBNP (ng/l) & $86 \pm 123$ \\
\hline LVMI $\left(g / m^{2}\right)$ & $82 \pm 17$ \\
\hline LVDVI $\left(\mathrm{ml} / \mathrm{m}^{2}\right)$ & $50 \pm 8$ \\
\hline LVSVI $\left(\mathrm{ml} / \mathrm{m}^{2}\right)$ & $19 \pm 4$ \\
\hline LAVI $\left(\mathrm{ml} / \mathrm{m}^{2}\right)$ & $27 \pm 6$ \\
\hline IVSI $\left(\mathrm{mm} / \mathrm{m}^{2}\right)$ & $5.1 \pm 0.5$ \\
\hline POSTI $\left(\mathrm{mm} / \mathrm{m}^{2}\right)$ & $4.5 \pm 0.4$ \\
\hline $\mathrm{EF}(\%)$ & $63 \pm 5$ \\
\hline$E(\mathrm{~cm} / \mathrm{s})$ & $76 \pm 20$ \\
\hline$A(\mathrm{~cm} / \mathrm{s})$ & $84 \pm 19$ \\
\hline E/A & $0.9 \pm 0.3$ \\
\hline DT (msec) & $218 \pm 44$ \\
\hline $\mathrm{S}(\mathrm{cm} / \mathrm{s})$ & $64 \pm 10$ \\
\hline$D(\mathrm{~cm} / \mathrm{s})$ & $49 \pm 14$ \\
\hline$S / D$ & $1.4 \pm 0.3$ \\
\hline Sm septal $(\mathrm{cm} / \mathrm{s})$ & $7.6 \pm 1.6$ \\
\hline Em septal $(\mathrm{cm} / \mathrm{s})$ & $6.7 \pm 1.4$ \\
\hline Am septal $(\mathrm{cm} / \mathrm{s})$ & $9.6 \pm 1.8$ \\
\hline Sm lateral $(\mathrm{cm} / \mathrm{s})$ & $8.9 \pm 1.6$ \\
\hline Em lateral $(\mathrm{cm} / \mathrm{s})$ & $8.7 \pm 2.6$ \\
\hline Am lateral $(\mathrm{cm} / \mathrm{s})$ & $1 \mathrm{I} .4 \pm 2.5$ \\
\hline $\mathrm{E} / \mathrm{Em}$ & $10.3 \pm 3.7$ \\
\hline Em/Am septal & $0.7 \pm 0.2$ \\
\hline Em/Am lateral & $0.8 \pm 0.3$ \\
\hline $\mathrm{Em} / \mathrm{Am}$ average & $0.7 \pm 0.2$ \\
\hline Sm right ventricle $(\mathrm{cm} / \mathrm{s})$ & $13.6 \pm 3.0$ \\
\hline Em right ventricle $(\mathrm{cm} / \mathrm{s})$ & $9.8 \pm 2.9$ \\
\hline Am right ventricle $(\mathrm{cm} / \mathrm{s})$ & $\mid 4.5 \pm 3.1$ \\
\hline
\end{tabular}

Abbreviations: BNP, brain natriuretic peptide; NT-proBNP, N-terminal pro brain natriuretic peptide. Indexed for BSA: POSTI, posterior wall thickness; IVSI, interventricularseptum thickness; LVMI, left ventricular mass; LVDVI, left ventricular end-diastolic volume; LVSVI, left ventricular end-systolic volume; LAVI, left atrial end-systolic volume; EF, ejection fraction; E, peak of early diastolic; A, late diastolic; mitral flow velocities. DT, deceleration time of E-wave; S, Pulmonary vein peak velocities systole; D, diastole. pulsed tissue Doppler imaging velocities; Sm, peak systolic; Em, early diastolic velocities; Am, late diastolic velocities. 
Table 2 Pearson correlation coefficients, with adjustment for sex, between in BNP and in NT-proBNP versus anthropometric and echocardiography parameters

\begin{tabular}{|c|c|c|}
\hline Echocardiography parameter & In BNP & In NT-proBNP \\
\hline Age (yrs) & 0.04 & 0.27 \\
\hline Height (cm) & 0.09 & 0.02 \\
\hline Body mass (kg) & $0.36 *$ & 0.17 \\
\hline BMI $\left(\mathrm{kg} / \mathrm{m}^{2}\right)$ & 0.32 & 0.14 \\
\hline $\mathrm{BSA}\left(\mathrm{m}^{2}\right)$ & 0.33 & 0.16 \\
\hline eGFR (ml/min) & 0.18 & -0.09 \\
\hline LVMI $\left(\mathrm{g} / \mathrm{m}^{2}\right)$ & 0.11 & 0.33 \\
\hline LVDVI (ml/m²) & 0.32 & 0.16 \\
\hline LVSVI $\left(\mathrm{ml} / \mathrm{m}^{2}\right)$ & 0.22 & 0.16 \\
\hline LAVI $\left(\mathrm{ml} / \mathrm{m}^{2}\right)$ & $0.62^{* *}$ & $0.60 * *$ \\
\hline IVSI $\left(\mathrm{mm} / \mathrm{m}^{2}\right)$ & -0.31 & 0.20 \\
\hline POSTI $\left(\mathrm{mm} / \mathrm{m}^{2}\right)$ & -0.25 & 0.06 \\
\hline $\mathrm{EF}(\%)$ & -0.05 & -0.10 \\
\hline $\mathrm{E}$ & 0.25 & 0.25 \\
\hline A & -0.12 & 0.16 \\
\hline E/A & 0.30 & 0.08 \\
\hline DT & -0.17 & -0.24 \\
\hline S & 0.02 & 0.19 \\
\hline D & 0.25 & 0.29 \\
\hline$S / D$ & -0.29 & -0.18 \\
\hline Sm septal & -0.21 & -0.11 \\
\hline Em septal & 0.15 & 0.18 \\
\hline Am septal & -0.24 & -0.21 \\
\hline Sm lateral & -0.29 & -0.11 \\
\hline Em lateral & -0.05 & -0.07 \\
\hline Am lateral & -0.05 & 0.07 \\
\hline $\mathrm{E} / \mathrm{Em}$ & 0.10 & 0.14 \\
\hline Em/Am septal & 0.31 & 0.32 \\
\hline Em/Am lateral & -0.05 & -0.11 \\
\hline $\mathrm{Em} / \mathrm{Am}$ average & 0.09 & 0.03 \\
\hline S right ventricle & 0.08 & 0.13 \\
\hline Em right ventricle & 0.25 & 0.15 \\
\hline Am right ventricle & -0.08 & -0.00 \\
\hline
\end{tabular}

Notes: *Indicate statistical significant correlation, $P<0.05$ and $* * P<0.001$. Indexed for BSA.

Abbreviations: POSTI, posterior wall thickness; IVSI, interventricularseptum thickness; LVMI, left ventricular mass; LVDVI, left ventricular end-diastolic volume; LVSVI, left ventricular end-systolic volume; LAVI, left atrial end-systolic volume; EF, ejection fraction; $E$, peak of early diastolic; A, late diastolic; mitral flow velocities. $\mathrm{DT}$, deceleration time of E-wave; S, pulmonary vein peak velocities systole; D, diastole. pulsed tissue Doppler imaging velocities: Sm, peak systolic; Em, early diastolic velocities; Am, late diastolic velocities.

\section{Discussion}

This study showed that very few echocardiography parameters were correlated with BNP or NT-proBNP levels in patients with poorly regulated type 2 diabetes, which partly contradicts previous studies in other diabetic populations.
The exception was LAVI, which showed moderate correlation with BNP or NT-proBNP levels. The relatively strong correlations that were found, in spite of the modest sample size, suggests a biologically relevant relationship. Furthermore, significant differences in BNP and NT-proBNP levels were found between the group with normal left ventricular diastolic function and the group with abnormal diastolic function. In contrast, no significant differences in BNP and NT-proBNP levels were found between the individuals with normal versus elevated filling pressures, as estimated by echocardiography. These findings should of course be viewed with a considerable amount of caution because of the modest sample size, but they do point out directions for further larger studies.

BNP and NT-proBNP, being peptide hormones released from the cardiac ventricles in response to myocyte stretch, have generated considerable attention in recent years and have been proposed as potential diagnostic and prognostic markers for cardiac disease. Natriuretic peptides are shown to correlate with measures of cardiac dysfunction. NT-proBNP also have been shown to be independent risk markers for cardiovascular disease in patients with diabetes. ${ }^{18-20}$ For example, a reduction of $10 \mathrm{pg} / \mathrm{mL}$ in NT-proBNP is associated with a $1 \%$ relative reduction in the cardiovascular endpoints in patients with type 1 diabetes and microalbuminuria. ${ }^{19}$

It is somewhat surprising that none of the Doppler and tissue Doppler parameters were related to BNP and NT-proBNP concentrations. This could, in part, be related to the known U-shape of most diastolic variables, with the exception of Em and E/Em. Additionally, the modest sample size could be a factor since several of the correlations went in the hypothesized direction but did not reach statistical significance. Equally surprising was the finding that very few patients were diagnosed with diastolic dysfunction, which could be explained by the heavy reliance on LAVI in the current classification of diastolic dysfunction. Whether this classification will survive the test of time remains to be seen. The finding that LAVI was moderately related to BNP and NT-proBNP levels is of interest since LAVI has been found to be a potent prognosticator in a variety of cardiac disorders and in the general population. ${ }^{21}$ Furthermore, LAVI has been suggested to serve as an expression of left ventricular filling pressures in individuals without atrial fibrillation or mitral valve disease. ${ }^{21}$ The underlying mechanism is that the left atrium is exposed to the pressures of the left ventricle during diastole. With increased stiffness or lack of compliance in the left ventricle the pressure rises to maintain adequate left ventricular filling, which leads to increased atrial wall 


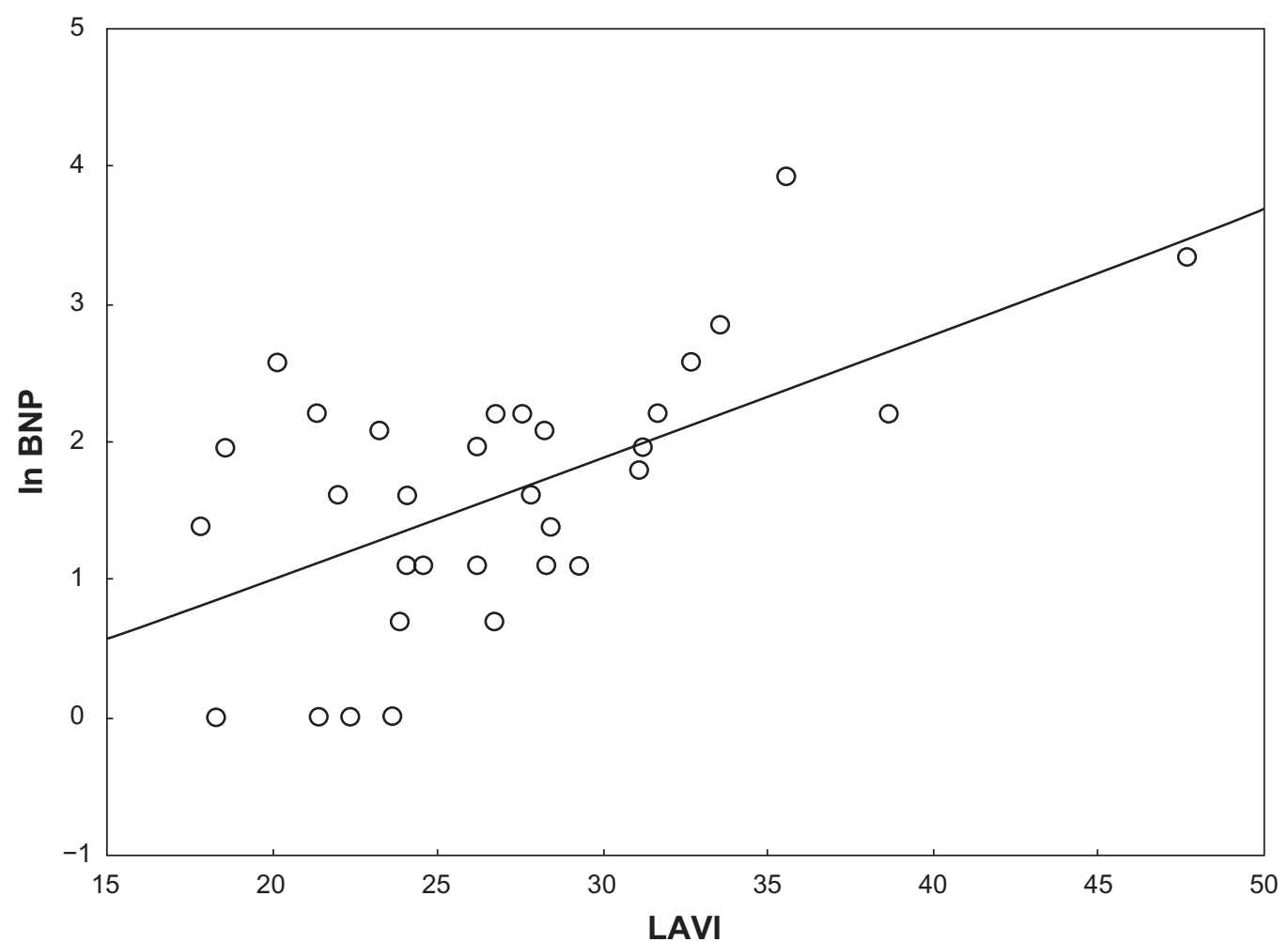

Figure I The figure displays the unadjusted relationship between left atrial end-systolic volume indexed for body surface area (BSA) indexed left atrial end-systolic volume (LAVI) and In brain natriuretic peptide (In BNP).

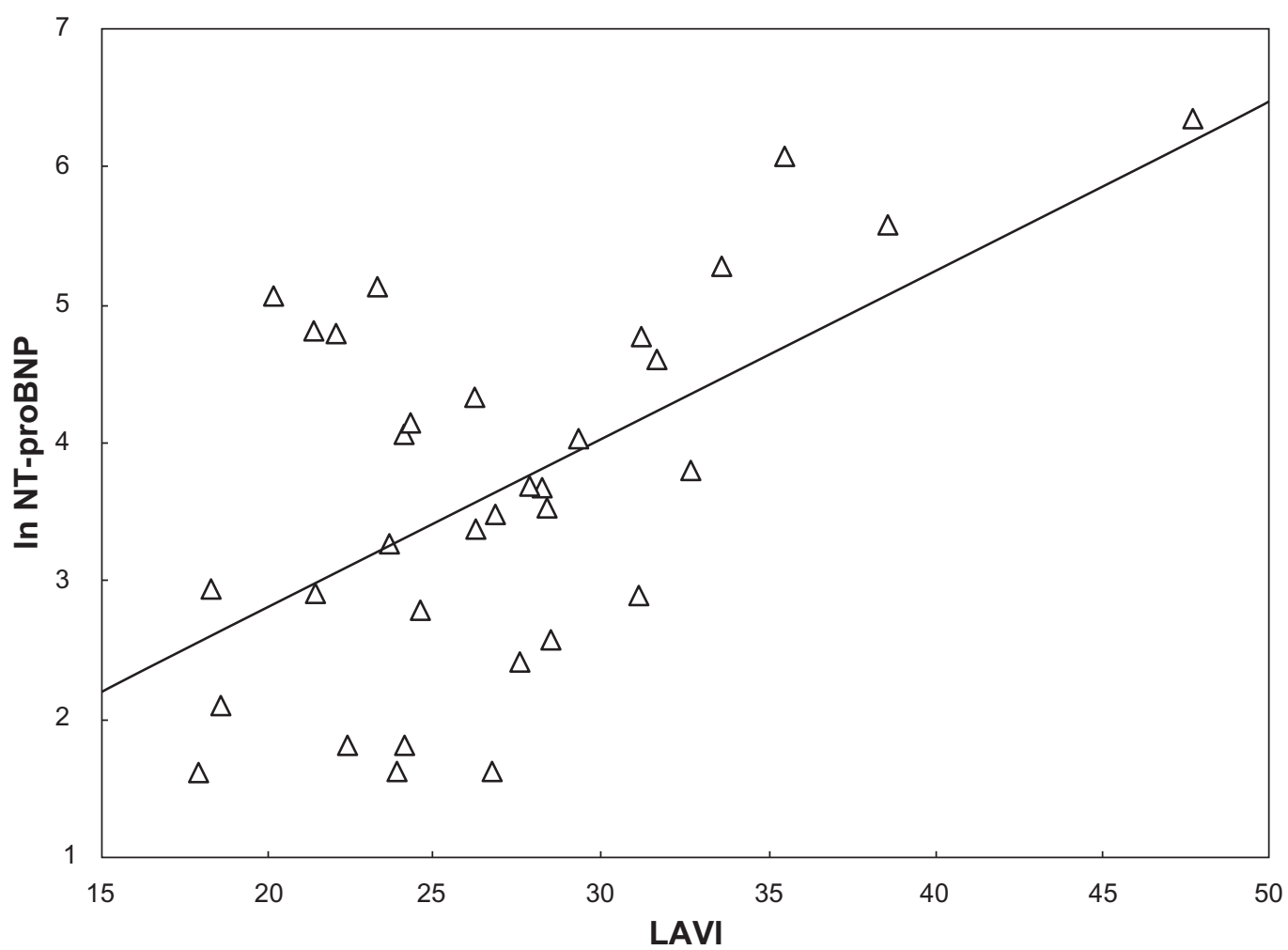

Figure 2 The figure displays the unadjusted relationship between left atrial end-systolic volume indexed for body surface area (BSA) indexed left atrial end-systolic volume (LAVI) and In N-terminal pro brain natriuretic peptide (In NT-proBNP). 
Table 3 Subjects' anthropometric, laboratory, and selected echocardiography characteristics. Values are mean \pm SD

\begin{tabular}{|c|c|c|c|}
\hline Variable & Normal & Abnormal & $P$-value \\
\hline Men/women & $20 / 9$ & $3 / 1$ & $>0.2$ \\
\hline Age (yrs) & $60.9 \pm 7.3$ & $65.3 \pm 7.3$ & $>0.2$ \\
\hline Height $(\mathrm{cm})$ & $170.4 \pm 9.1$ & $174.3 \pm 9.1$ & $>0.2$ \\
\hline Body mass (kg) & $89.3 \pm 16.8$ & $98.5 \pm 16.8$ & $>0.2$ \\
\hline BMI $\left(\mathrm{kg} / \mathrm{m}^{2}\right)$ & $30.8 \pm 5.6$ & $32.7 \pm 5.6$ & $>0.2$ \\
\hline $\mathrm{BSA}\left(\mathrm{m}^{2}\right)$ & $2.0 \pm 0.2$ & $2.1 \pm 0.2$ & $>0.2$ \\
\hline Diabetes duration (years) & $9.1 \pm 5.3$ & $15.0 \pm 5.3$ & 0.08 \\
\hline $\mathrm{HbA}_{\mathrm{Ic}}(\%)$ & $8.1 \pm 1.3$ & $9.0 \pm 1.3$ & $>0.2$ \\
\hline Systolic blood pressure $(\mathrm{mm} \mathrm{Hg})$ & $141.1 \pm 15.3$ & $161.0 \pm 15.4$ & 0.02 \\
\hline Diastolic blood pressure (mm Hg) & $82.0 \pm 7.8$ & $86.5 \pm 7.8$ & $>0.2$ \\
\hline eGFR (ml/min) & $118 \pm 40$ & $116 \pm 38$ & $>0.20$ \\
\hline BNP (pmol/l) & $5.3 \pm 3.4$ & $26.0 \pm 3.4$ & $<0.001$ \\
\hline In BNP & $1.4 \pm 0.8$ & $3.1 \pm 0.8$ & $<0.001$ \\
\hline NT-proBNP (ng/l) & $48.3 \pm 47.4$ & $360.0 \pm 47.4$ & $<0.001$ \\
\hline In NT-proBNP & $3.4 \pm 1.1$ & $5.8 \pm 1.1$ & $<0.001$ \\
\hline LVMI $\left(\mathrm{g} / \mathrm{m}^{2}\right)$ & $80.7 \pm 16.6$ & $93.2 \pm 16.6$ & 0.17 \\
\hline LVDVI $\left(\mathrm{ml} / \mathrm{m}^{2}\right)$ & $49.4 \pm 7.8$ & $56.8 \pm 7.8$ & 0.07 \\
\hline LVSVI $\left(\mathrm{ml} / \mathrm{m}^{2}\right)$ & $18.3 \pm 4.3$ & $21.1 \pm 4.3$ & $>0.20$ \\
\hline LAVI $\left(\mathrm{ml} / \mathrm{m}^{2}\right)$ & $25.2 \pm 4.1$ & $38.9 \pm 4.1$ & $<0.001$ \\
\hline IVSI $\left(\mathrm{mm} / \mathrm{m}^{2}\right)$ & $5.1 \pm 0.4$ & $5.2 \pm 0.4$ & $>0.2$ \\
\hline POSTI $\left(\mathrm{mm} / \mathrm{m}^{2}\right)$ & $4.5 \pm 0.4$ & $4.5 \pm 0.4$ & $>0.2$ \\
\hline $\mathrm{EF}(\%)$ & $63.1 \pm 5.2$ & $63.0 \pm 5.2$ & $>0.2$ \\
\hline E/A & $0.9 \pm 0.3$ & $\mathrm{I} . \mathrm{I} \pm 0.3$ & $>0.2$ \\
\hline DT (msec) & $219 \pm 44$ & $211 \pm 44$ & $>0.2$ \\
\hline$S / D$ & $1.4 \pm 0.3$ & $1.2 \pm 0.3$ & $>0.2$ \\
\hline $\mathrm{E} / \mathrm{Em}$ & $10.0 \pm 3.6$ & $12.5 \pm 3.6$ & 0.20 \\
\hline Sm septal $(\mathrm{cm} / \mathrm{s})$ & $7.6 \pm 1.7$ & $7.2 \pm 1.7$ & $>0.2$ \\
\hline Em septal $(\mathrm{cm} / \mathrm{s})$ & $6.7 \pm 1.4$ & $7.0 \pm 1.4$ & $>0.2$ \\
\hline Am septal $(\mathrm{cm} / \mathrm{s})$ & $9.7 \pm 1.8$ & $8.2 \pm 1.8$ & 0.09 \\
\hline Sm lateral $(\mathrm{cm} / \mathrm{s})$ & $9.1 \pm 1.5$ & $7.5 \pm 1.5$ & 0.07 \\
\hline Em lateral $(\mathrm{cm} / \mathrm{s})$ & $8.8 \pm 2.7$ & $8.3 \pm 2.7$ & $>0.2$ \\
\hline Am lateral $(\mathrm{cm} / \mathrm{s})$ & $11.6 \pm 2.4$ & $9.8 \pm 2.4$ & 0.19 \\
\hline
\end{tabular}

Notes: The study population is divided into those with normal versus abnormal diastolic function.

Abbreviations: BNP, brain natriuretic peptide; NT-proBNP, N-terminal pro brain natriuretic peptide. Indexed for BSA: POSTI, posterior wall thickness; IVSI, interventricularseptum thickness; LVMI, left ventricular mass; LVDVI, left ventricular end-diastolic volume; LVSVI, left ventricular end-systolic volume; LAVI, left atrial end-systolic volume; $\mathrm{EF}$, ejection fraction; E, peak of early diastolic; $\mathrm{A}$, late diastolic; mitral flow velocities. DT, deceleration time of E-wave; $\mathrm{S}$, pulmonary vein peak velocities systole; $\mathrm{D}$, diastole. pulsed tissue Doppler imaging velocities; Sm, peak systolic; Em, early diastolic velocities; Am, late diastolic velocities.

tension and subsequent dilatation. Moreover, LAVI has been suggested to better express the long standing exposure to elevated filling pressures caused by left ventricular diastolic dysfunction than more load dependent parameters such as Doppler and TDI. ${ }^{21}$ This aspect could in part explain why no significant differences in BNP and NT-proBNP levels were found between the individuals with normal versus elevated filling pressures. The initial validation studies of the E/Em index as a way of estimating filling pressure by echocardiography were very promising. ${ }^{22-24}$ A recent study has, however, raised significant concern about the use of the $\mathrm{E} / \mathrm{Em}$ index for estimation of filling pressures. ${ }^{25}$ Moreover, the E/Em index has not been validated, as a estimate of filling pressure, in diabetic populations. ${ }^{22-25}$

We have been able to identify four previous studies examining the relationship between BNP and NT-proBNP 


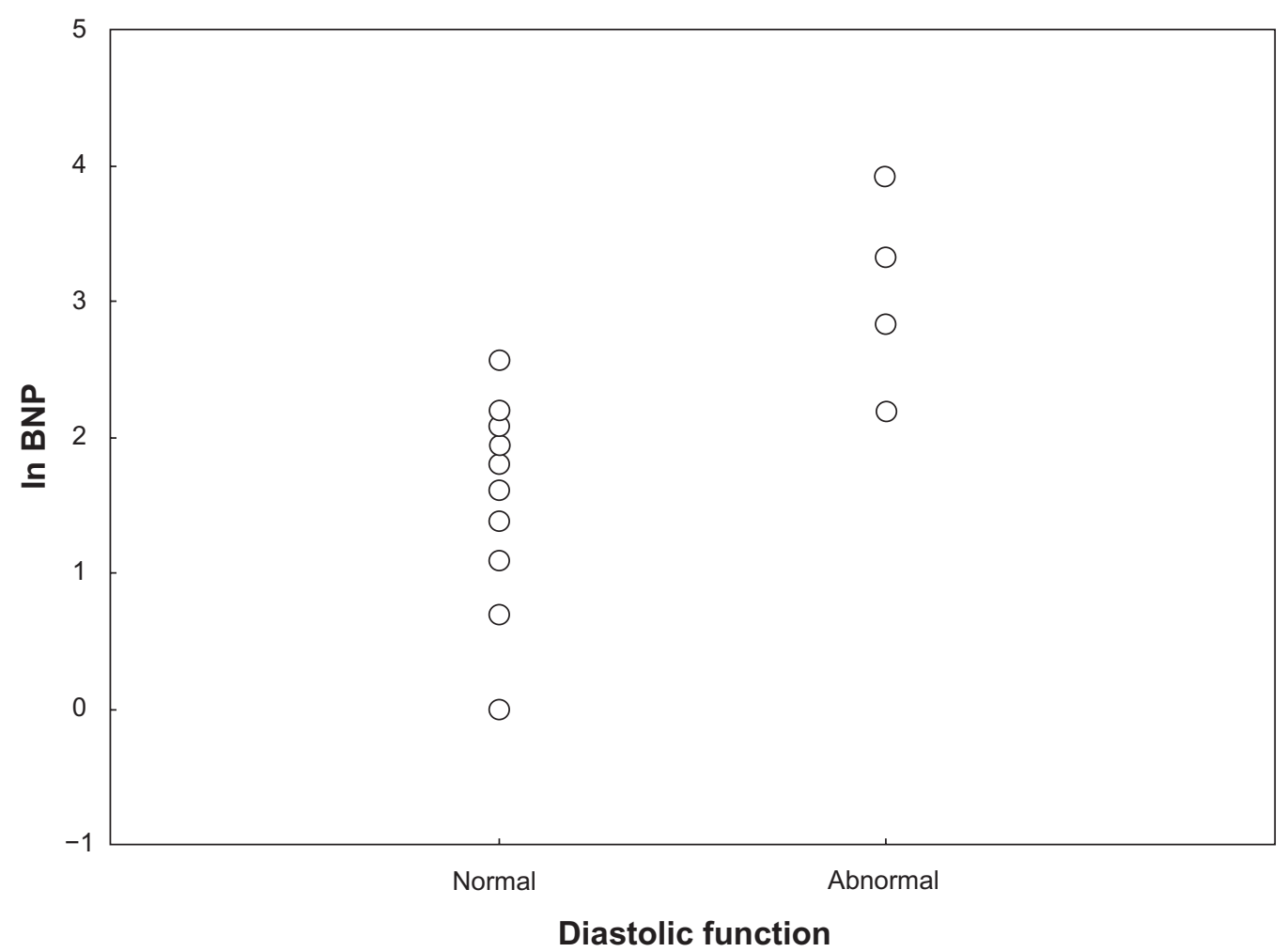

Figure 3 The figure displays the study population according to classification of left ventricular diastolic function and levels of In brain natriuretic peptide (In BNP).

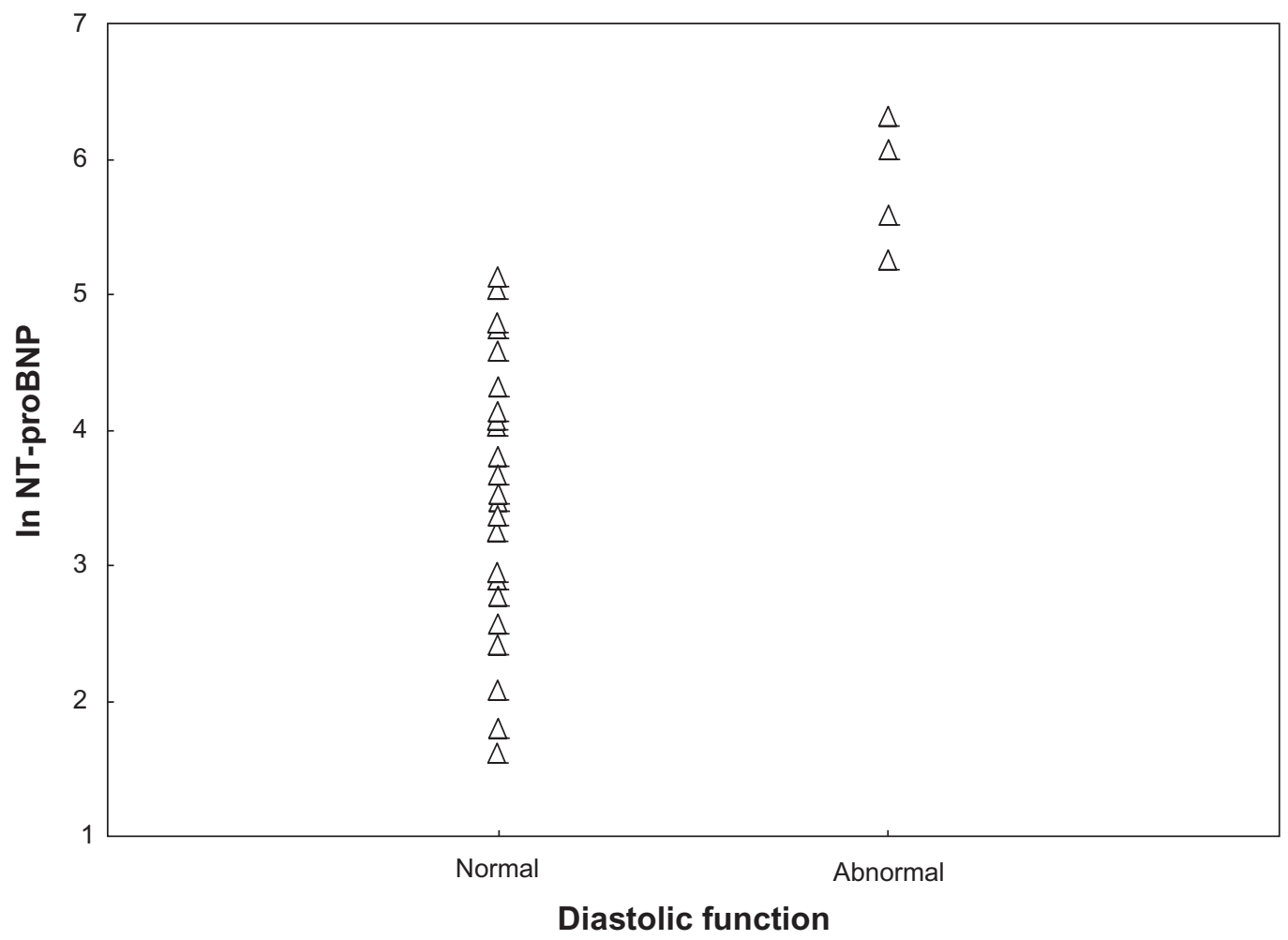

Figure 4 The figure displays the study population according to classification of left ventricular diastolic function and levels of In $\mathrm{N}$-terminal pro brain natriuretic peptide (In NT-proBNP). 
Table 4 Subjects' anthropometric, laboratory, and selected echocardiography characteristics

\begin{tabular}{|c|c|c|c|}
\hline Variable & Normal & Elevated & $P$-value \\
\hline Men/women & $19 / 6$ & $4 / 4$ & 0.17 \\
\hline Age (yrs) & $61.5 \pm 7.1$ & $61.0 \pm 8.9$ & $>0.20$ \\
\hline Height $(\mathrm{cm})$ & $172 \pm 7$ & $167 \pm 10$ & 0.13 \\
\hline Body mass (kg) & $90 \pm 17$ & $93 \pm 15$ & $>0.20$ \\
\hline BMI $\left(\mathrm{kg} / \mathrm{m}^{2}\right)$ & $30.1 \pm 5.0$ & $33.7 \pm 6.8$ & 0.12 \\
\hline BSA $\left(m^{2}\right)$ & $2.0 \pm 0.2$ & $2.0 \pm 0.2$ & $>0.20$ \\
\hline Diabetes duration (years) & $9.0 \pm 5.9$ & $12.5 \pm 7.1$ & 0.17 \\
\hline $\mathrm{HbA}_{\mathrm{Ic}}(\%)$ & $7.9 \pm 1.0$ & $9.2 \pm 2.0$ & 0.02 \\
\hline Systolic blood pressure $(\mathrm{mm} \mathrm{Hg})$ & $142 \pm 17$ & $147 \pm 17$ & $>0.20$ \\
\hline Diastolic blood pressure (mm Hg) & $82 \pm 8$ & $83 \pm 5$ & $>0.20$ \\
\hline eGFR (ml/min) & $114 \pm 36$ & $|29 \pm 5|$ & 0.20 \\
\hline BNP (pmol/l) & $6.5 \pm 5.9$ & $11.9 \pm 15.9$ & 0.16 \\
\hline In BNP & $1.5 \pm 0.9$ & $1.9 \pm 1.2$ & $>0.20$ \\
\hline NT-proBNP (ng/l) & $74 \pm 115$ & $123 \pm 149$ & $>0.20$ \\
\hline In NT-proBNP & $3.5 \pm 1.3$ & $4.0 \pm 1.5$ & $>0.20$ \\
\hline LVMI $\left(g / m^{2}\right)$ & $83.7 \pm 16.5$ & $77.6 \pm 17.8$ & $>0.20$ \\
\hline LVDVI $\left(\mathrm{ml} / \mathrm{m}^{2}\right)$ & $50.4 \pm 8.1$ & $50.1 \pm 7.0$ & $>0.20$ \\
\hline LVSVI $\left(\mathrm{ml} / \mathrm{m}^{2}\right)$ & $18.9 \pm 4.5$ & $18.0 \pm 3.6$ & $>0.20$ \\
\hline LAVI $\left(\mathrm{ml} / \mathrm{m}^{2}\right)$ & $26.1 \pm 6.0$ & $29.4 \pm 6.7$ & $>0.20$ \\
\hline IVSI $\left(\mathrm{mm} / \mathrm{m}^{2}\right)$ & $5.2 \pm 0.4$ & $4.9 \pm 0.6$ & 0.07 \\
\hline POSTI $\left(\mathrm{mm} / \mathrm{m}^{2}\right)$ & $4.5 \pm 0.4$ & $4.3 \pm 0.4$ & 0.08 \\
\hline $\mathrm{EF}(\%)$ & $63 \pm 5$ & $64 \pm 5$ & $>0.20$ \\
\hline E/A & $0.9 \pm 0.3$ & $1.0 \pm 0.3$ & $>0.20$ \\
\hline DT (msec) & $222 \pm 44$ & $207 \pm 44$ & $>0.20$ \\
\hline$S / D$ & $1.4 \pm 0.2$ & $1.4 \pm 0.4$ & $>0.20$ \\
\hline $\mathrm{E} / \mathrm{Em}$ & $8.6 \pm 1.7$ & $15.6 \pm 3.1$ & $<0.001$ \\
\hline Sm septal $(\mathrm{cm} / \mathrm{s})$ & $7.9 \pm 1.7$ & $6.7 \pm 1.0$ & 0.08 \\
\hline Em septal $(\mathrm{cm} / \mathrm{s})$ & $7.0 \pm 1.4$ & $5.8 \pm 1.2$ & 0.03 \\
\hline Am septal $(\mathrm{cm} / \mathrm{s})$ & $9.9 \pm 1.7$ & $8.4 \pm 1.6$ & 0.04 \\
\hline Sm lateral $(\mathrm{cm} / \mathrm{s})$ & $9.2 \pm 1.4$ & $8.0 \pm 1.8$ & 0.07 \\
\hline Em lateral $(\mathrm{cm} / \mathrm{s})$ & $9.3 \pm 2.7$ & $7.0 \pm 1.8$ & 0.04 \\
\hline Am lateral $(\mathrm{cm} / \mathrm{s})$ & $11.2 \pm 2.0$ & $11.9 \pm 3.7$ & $>0.20$ \\
\hline
\end{tabular}

Notes: Values are mean \pm SD. The study population is divided into those with normal versus elevated filling pressure estimated by echocardiography.

Abbreviations: BNP, brain natriuretic peptide; NT-proBNP, N-terminal pro brain natriuretic peptide. Indexed for BSA: POSTI, Pposterior wall thickness; IVSI, interventricularseptum thickness; LVMI, left ventricular mass; LVDVI, left ventricular end-diastolic volume; LVSVI, left ventricular end-systolic volume; LAVI, left atrial end-systolic volume; EF, ejection fraction; E, peak of early diastolic; A, late diastolic; mitral flow velocities. DT, deceleration time of E-wave; S, pulmonary vein peak velocities systole; D, diastole. pulsed tissue Doppler imaging velocities; Sm, peak systolic; Em, early diastolic velocities; Am, late diastolic velocities.

versus echocardiography in diabetic patients. ${ }^{11-14}$ These studies consist of diverging diabetic populations and diverging echocardiography protocols. Epshteyn et al investigated a mixed US population of 486 patients, $88 \%$ T2D and 12\% type 1 diabetes. ${ }^{13}$ Raised BNP levels were found to predict abnormal left ventricular function defined as $\mathrm{EF}<50 \%$ or abnormal diastolic function based solely on Doppler findings. Fang et al studied 101 unselected asymptomatic patients with T2D. ${ }^{11}$ In this study, subclinical left ventricular disease as measured by Doppler and tissue Doppler could not be predicted by BNP. Similar findings were found by Valle et al, who investigated 79 T2D patients without known heart disease. ${ }^{12}$ In contrast, Shimabukuro et al found that BNP levels could predict left ventricular diastolic dysfunction, as measured only by Doppler, in 98 T2D patients without known heart 
disease. ${ }^{14}$ The relationship between LAVI or the current classification of left ventricular diastolic function and BNP and NT-proBNP concentration has not been investigated in previous studies. ${ }^{11-14}$

Echocardiography is considered a "gold standard" method, in daily clinical practice, for evaluating cardiac function. However, due to its limited availability and costs, it is not possible to use in larger groups of patients. Natriuretic peptides on the other hand are readily available and relatively inexpensive. There is consensus that natriuretic peptides are useful in screening for cardiovascular disease, especially in symptomatic patient populations. ${ }^{6}$

Furthermore, natriuretic peptides carry powerful prognostic information. ${ }^{6}$ There are, however, currently no clear algorithms on how these biomarkers should be implemented into clinical practice in patients with T2D. In a population of patients with type 2 diabetes and drug failure (the subjects of this study) there is a need for combination therapy to achieve glycemic goals. Add on treatments with insulin and/or thiazolidinediones are among common treatment strategies. ${ }^{9}$ However, these regimens may cause fluid retention, weight gain, and in a few cases, heart failure. Our results support, in part, an initial assessment of a natriuretic peptide to identify individuals who have preexisting heart dysfunction, despite the modest sample size.

\section{Conclusion}

This pilot study showed that very few echocardiography parameters correlated with BNP or NT-proBNP levels in a population of patients with poorly regulated T2D. The exception was LAVI, which showed a moderate correlation with BNP or NT-proBNP levels. Moreover, significant differences in BNP and NT-proBNP levels were found between those with normal and those with abnormal left ventricular diastolic function according to current classifications. Larger studies are warranted to confirm these findings. There is a need for tools to help clinicians to risk stratify subsets of patients who are likely to have particularly unfavorable prognoses, using readily identifiable clinical and laboratory factors. Knowledge is increasing in this field and, hopefully, the results will enable clinicians to identify patients with increased risk of developing adverse events, thereby choosing an individualized treatment and monitoring scheme for each patient. Data on patients with poorly regulated T2D are scarce and the findings in the present investigation points out a direction for further larger studies.

\section{Acknowledgments}

Cardiac sonographer Ingrid Andersson is acknowledged for acquiring echocardiography images. The study was in part financially supported by grants from Sanofi-Aventis, The Crafoord Foundation, and The Swedish Heart and Lung Association. The authors of this manuscript have certified that they comply with the Principles of Ethical Publishing in the International Journal of Cardiology.

\section{Disclosure}

Magnus Dencker has no conflict of interest to declare. Martin Stagmo has received speaker's fees from Sanofi-Aventis and through his spouse owns shares and stock options in NovoNordisk A/S. Mozhgan Dorkhan has served as speaker for Eli Lilly and Novartis, and received a scholarship from Sanofi-Aventis.

\section{References}

1. Kannel WB, Hjortland M, Castelli WP. Role of diabetes in congestive heart failure: the Framingham study. Am J Cardiol. 1974;34:29-34.

2. Haffner SM, Lehto S, Ronnemaa T, Pyorala K, Laakso M. Mortality from coronary heart disease in subjects with type 2 diabetes and in nondiabetic subjects with and without prior myocardial infarction. N Engl J Med. 1998;339:229-234.

3. Stratton IM, Adler AI, Neil HA, Matthews DR, Manley SE, Cull CA, Hadden D, et al. Association of glycaemia with macrovascular and microvascular complications of type 2 diabetes (UKPDS 35): prospective observational study. BMJ. 2000;321:405-412.

4. Rana BS, Davies JI, Band MM, Pringle SD, Morris A, Struthers AD. B-type natriuretic peptide can detect silent myocardial ischaemia in asymptomatic type 2 diabetes. Heart. 2006;92:916-920.

5. Schuijf JD, Achenbach S, Zoghbi WA, et al. How to identify the asymptomatic high-risk patient? Curr Probl Cardiol. 2009;34: 539-577.

6. Maisel A, Mueller C, Adams K Jr, et al. State of the art: using natriuretic peptide levels in clinical practice. Eur J Heart Fail. 2008;10:824-839.

7. Braunwald E. Biomarkers in heart failure. $N$ Engl J Med. 2008;358 2148-2159.

8. Penney MD. Natriuretic peptides and the heart: current and future implications for clinical biochemistry. Ann Clin Biochem. 2005;42: 432-440.

9. Nathan DM, Buse JB, Davidson MB, et al. Management of hyperglycemia in type 2 diabetes: a consensus algorithm for the initiation and adjustment of therapy: update regarding thiazolidinediones: a consensus statement from the American Diabetes Association and the European Association for the Study of Diabetes. Diabetes Care. 2008;31: 173-175.

10. Singh S, Loke YK, Furberg CD. Thiazolidinediones and heart failure: a teleo-analysis. Diabetes Care. 2007;30:2148-2153.

11. Fang ZY, Schull-Meade R, Leano R, Mottram PM, Prins JB, Marwick TH. Screening for heart disease in diabetic subjects. Am Heart J. 2005;149:349-354.

12. Valle R, Bagolin E, Canali C, et al. The BNP assay does not identify mild left ventricular diastolic dysfunction in asymptomatic diabetic patients. Eur J Echocardiogr. 2006;7:40-44.

13. Epshteyn V, Morrison K, Krishnaswamy P, et al. Utility of B-type natriuretic peptide (BNP) as a screen for left ventricular dysfunction in patients with diabetes. Diabetes Care. 2003;26: 2081-2087. 
14. Shimabukuro M, Higa N, Oshiro Y, Asahi T, Takasu N. Diagnostic utility of brain-natriuretic peptide for left ventricular diastolic dysfunction in asymptomatic type 2 diabetic patients. Diabetes Obes Metab. 2007;9:323-329.

15. Du Bois D, Du Bois EF. A formula to estimate the approximate surface area if height and weight be known. Arch Intern Med. 1916;17:863-871.

16. Lang RM, Bierig M, Devereux RB, et al. Recommendations for chamber quantification: a report from the American Society of Echocardiography's Guidelines and Standards Committee and the Chamber Quantification Writing Group, developed in conjunction with the European Association of Echocardiography, a branch of the European Society of Cardiology. J Am Soc Echocardiogr. 2005;18:1440-1463.

17. Nagueh SF, Appleton CP, Gillebert TC, et al. Recommendations for the evaluation of left ventricular diastolic function by echocardiography. $J$ Am Soc Echocardiogr. 2009;22:107-133.

18. Bhalla MA, Chiang A, Epshteyn VA, et al. Prognostic role of B-type natriuretic peptide levels in patients with type 2 diabetes mellitus. $\mathrm{J} \mathrm{Am}$ Coll Cardiol. 2004;44:1047-1052.

19. Gaede P, Hildebrandt P, Hess G, Parving HH, Pedersen O. Plasma $\mathrm{N}$-terminal pro-brain natriuretic peptide as a major risk marker for cardiovascular disease in patients with type 2 diabetes and microalbuminuria. Diabetologia. 2005;48:156-163.
20. Tarnow L, Hildebrandt P, Hansen BV, Borch-Johnsen K, Parving HH. Plasma N-terminal pro-brain natriuretic peptide as an independent predictor of mortality in diabetic nephropathy. Diabetologia. 2005;48:149-155.

21. Abhayaratna WP, Seward JB, Appleton CP, et al. Left atrial size: physiologic determinants and clinical applications. J Am Coll Cardiol. 2006;47:2357-2363.

22. Sohn DW, Chai IH, Lee DJ, et al. Assessment of mitral annulus velocity by Doppler tissue imaging in the evaluation of left ventricular diastolic function. J Am Coll Cardiol. 1997;30:474-480.

23. Nagueh SF, Middleton KJ, Kopelen HA, Zoghbi WA, Quiñones MA. Doppler tissue imaging: a noninvasive technique for evaluation of left ventricular relaxation and estimation of filling pressures. $\mathrm{J} \mathrm{Am} \mathrm{Coll}$ Cardiol. 1997;30:1527-1533.

24. Ommen SR, Nishimura RA, Appleton CP, et al. Clinical utility of Doppler echocardiography and tissue Doppler imaging in the estimation of left ventricular filling pressures: A comparative simultaneous Doppler-catheterization study. Circulation. 2000;102:1788-1794.

25. Mullens W, Borowski AG, Curtin RJ, Thomas JD, Tang WH. Tissue Doppler imaging in the estimation of intracardiac filling pressure in decompensated patients with advanced systolic heart failure. Circulation. 2009;119:62-70.
Vascular Health and Risk Management

\section{Publish your work in this journal}

Vascular Health and Risk Management is an international, peerreviewed journal of therapeutics and risk management, focusing on concise rapid reporting of clinical studies on the processes involved in the maintenance of vascular health; the monitoring, prevention and treatment of vascular disease and its sequelae; and the involvement of

\section{Dovepress}

metabolic disorders, particularly diabetes. This journal is indexed on PubMed Central and MedLine. The manuscript management system is completely online and includes a very quick and fair peer-review system, which is all easy to use. Visit http://www.dovepress.com/ testimonials.php to read real quotes from published authors. 